NBER WORKING PAPER SERIES

\title{
A NOTE ON THE EMPIRICAL IMPLEMENTATION OF LENS CONDITION
}

\author{
Andrew B. Bernard \\ Raymond Robertson \\ Peter K. Schott \\ Working Paper 11448 \\ http://www.nber.org/papers/w11448
NATIONAL BUREAU OF ECONOMIC RESEARCH 1050 Massachusetts Avenue
Cambridge, MA 02138
June 2005

Bernard and Schott gratefully acknowledge research support from the National Science Foundation (SES0241474). We would like to thank Tom Halverson and Juan Camilo Gomez for helpful discussions. The views expressed and any errors are the authors' responsibility. Bernard: 100 Tuck Hall, Hanover, NH 03755; tel : (603) 646-0302, fax : (603)646-1308, email :andrew.b.bernard@dartmouth.edu. Robertson: 1600 Grand Ave. St. Paul, MN 55105; tel : (651) 696-6739, fax : (651) 696-6746, email :robertson@macalester.edu. Schott: 135 Prospect Street, New Haven, CT 06520; tel : (203) 436-4260, fax : (203) 432-6974, email :peter.schott@yale.edu. The views expressed herein are those of the author(s) and do not necessarily reflect the views of the National Bureau of Economic Research.

(C2005 by Andrew B. Bernard, Raymond Robertson, and Peter K. Schott. All rights reserved. Short sections of text, not to exceed two paragraphs, may be quoted without explicit permission provided that full credit, including (C) notice, is given to the source. 
A Note on the Empirical Implementation of the Lens Condition Andrew B. Bernard, Raymond Robertson, and Peter K. Schott NBER Working Paper No. 11448

June 2005

JEL No. F11, F16

\title{
ABSTRACT
}

Deardorff [Journal of International Economics 36 (1994) 167-175] offers an intuitively appealing test for factor price equality (FPE). He demonstrates that FPE is impossible if the set (i.e., lens) of points defined by regional factor abundance vectors does not lie within the set of points defined by goods' input intensities. This note demonstrates that empirical implementation of the lens condition is problematic if the "true" number of either goods or regions is unknown. We show that satisfaction of the lens condition is more likely when goods are relatively disaggregate compared to regions.

\author{
Andrew B. Bernard \\ Tuck School of Business Administration \\ Dartmouth College \\ 100 Tuck Hall \\ Hanover, NH 03755 \\ and NBER \\ andrew.b.bernard@dartmouth.edu \\ Raymond Robertson \\ Department of Economics \\ Macalester College \\ 1600 Grand Avenue \\ Saint Paul, MN 55105 \\ robertson@macalester.edu \\ Peter K. Schott \\ Yale School of Management \\ 135 Prospect Street \\ New Haven, CT 06520-8500 \\ and NBER \\ peter.schott@yale.edu
}




\section{Introduction}

Deardorff (1994) derives a condition for assessing the existence of factor price equality (FPE) across countries. This "lens condition" requires factor endowments to vary less across countries than factor input intensities vary across goods. Deardorff demonstrates that if the set points (i.e., lens) defined by regional factor abundances passes outside the set of points defined by goods' factor intensities, FPE is impossible.

Deardorff's theoretical analysis has been extended by Qi (2003), Demiroglu and Yun (1999), Xiang (2001), Yun (2003) and Wong and Yun (2003). These extensions reveal that satisfaction of the lens condition, while necessary and sufficient for FPE in the two-factor, many-good and many-country case, is necessary but not sufficient for FPE in settings with more than two factors. Thus, while violation of the lens condition may be useful for ruling out FPE, a lack of violation does not indicate support for FPE.

The lens condition has been used empirically to test for FPE both across countries internationally and across regions within countries. These tests suggest that FPE does not hold across developed and developing countries but likely holds across regions within countries. ${ }^{1}$

In this paper we argue that, even in the two factor case, the researcher's lack of knowledge about the "true" number of goods and regions forestalls useful empirical application of the lens condition. This unfortunate conclusion is due to the influence of data aggregation on lens size. Lenses created with more disaggregate data are larger than

\footnotetext{
${ }^{1}$ Debaere and Demiroglu (2003) show that lenses defined by country relative endowments pass outside lenses defined by the industries they produce. Debaere (2004) uses the lens condition to argue that regions within Japan, the United Kingdom and India exhibit factor price equalization.
} 
the lenses created with more aggregate data. ${ }^{2}$ As a result, satisfaction of the lens condition is more likely when industries are relatively disaggregated compared to countries or regions. Because the "true" relative level of aggregation is unknown, the outcome achieved by any particular level of relative aggregation is difficult to interpret.

Theory, unfortunately, offers little guidance for this problem. A lens test of FPE should be based on regions that individually exhibit constant factor rewards, i.e., FPE is known to hold inside each region. However, it is unclear how to identify these areas unless the existence of FPE is already known. Empirically defining industries, or more precisely, empirically identifying goods and their factor usages, presents similar challenges. ${ }^{3}$

This note proceeds as follows. In section II we show formally that industry disaggregation increases lens area. In section III, we demonstrate empirically the sensitivity of the lens condition to data aggregation using data on Mexican states. Section IV concludes.

\section{Data Disaggregation Increases Lens Area}

In this section we briefly describe Deardorff's (1994) lens condition before formally demonstrating the influence that data aggregation has on its empirical implementation.

\footnotetext{
${ }^{2}$ Debaere (2004) notes that use of more disaggregate industries increases the size of the factor-use lens. ${ }^{3}$ Davis and Weinstein (2001) and Schott (2003), for example, demonstrate important cross-country and intra-industry heterogeneity in production data commonly used to test the implications of neoclassical trade theory. Schott (2004) finds that such heterogeneity exists even within very narrowly defined products.
} 


\section{A. The Lens Condition}

Deardorff's (1994) lens condition is based on Dixit and Norman's (1980) concept of an integrated world economy (IWE), which has both factors and goods being perfectly mobile across countries. An IWE equilibrium is characterized by a certain level of output for each good and a single set of goods prices, factor rewards, and production techniques. If it is possible to replicate an IWE equilibrium with factor immobility by assigning factors to regions and goods, then FPE is possible. If such an allocation is not possible, FPE is not possible.

An IWE equilibrium can be replicated - and FPE is possible - if factor endowments vary less across regions than factor intensities vary across goods. More formally, this condition requires the set of points defined by regional factor abundances to lie inside the set of points defined by goods' factor usage. Figure 1 illustrates this condition via a Lerner diagram for two goods, two countries and two factors. The axes represent regions' endowments and goods' use of skilled (N) and unskilled (P) workers, respectively. ${ }^{4}$ The solid lenses in each panel are made up of four input vectors: the part of the lens above the diagonal sorts the vectors for the two goods in order of decreasing skill intensity, while the portion of the lens below the diagonal sorts them according to increasing skill intensity. The dashed lines define the region lenses in analogous fashion.

In the top panel of the figure, the lens condition is satisfied because the region lens lies within the goods lens. In the bottom panel the lens condition is violated.

We now examine how the relative size (area) of industry and region lenses depends upon data aggregation.

\footnotetext{
${ }^{4} \mathrm{~N}$ and $\mathrm{P}$ refer to our use of non-production (skilled) and production (unskilled) workers, respectively, in the empirical estimations below.
} 


\section{B. Lens Area and Data Aggregation}

There are $\mathrm{R}$ regions (indexed by $\mathrm{r}=1 \ldots \mathrm{R}$ ) and $\mathrm{G}$ goods (indexed by $\mathrm{i}=1 \ldots \mathrm{G}$ ). If $\mathrm{R}$ and $\mathrm{G}$ are known and the appropriate data on their factor endowments and factor usages exist, proper lenses can be constructed and a test of the lens condition empirically implemented. More generally the true number of regions and goods, R and G, are not known.

Consider two factors, skilled workers and unskilled workers. All goods use, and all regions are endowed with, nonnegative amounts of each factor. Let each region's share of skilled and unskilled workers be represented by the pair $\left(\mathrm{n}_{\mathrm{r}}, \mathrm{p}_{\mathrm{r}}\right)$, so that $0<\mathrm{n}_{\mathrm{r}}<1$ and $0<\mathrm{p}_{\mathrm{r}}<1$. Let $\left(\mathrm{N}_{\mathrm{r}}, \mathrm{P}_{\mathrm{r}}\right)$ represent region r's cumulative share of skilled and unskilled workers, i.e., the sum of the shares of regions 1 through $r$.

Sort regions according to decreasing skill abundance, so that the vector of $\mathrm{R}+1$ ordinate pairs

$$
\left[(0,0),\left(\mathrm{N}_{1}, \mathrm{P}_{1}\right), \ldots\left(\mathrm{N}_{\mathrm{r}}, \mathrm{P}_{\mathrm{r}}\right),\left(\mathrm{N}_{\mathrm{R}-1}, \mathrm{P}_{\mathrm{R}-1}\right),(1,1)\right],
$$

traces out the part of the regional endowment lens that lies above the diagonal. The other half of the lens, i.e., the portion that lies below the diagonal, is found by reconstructing the cumulative shares in (1) after sorting regions in terms of increasing skill abundance.

An analogous lens for factor use can be constructed, where

$$
\left[(0,0),\left(\mathrm{N}_{1}, \mathrm{P}_{1}\right), \ldots .\left(\mathrm{N}_{\mathrm{i}} \mathrm{P}_{\mathrm{i}}\right),\left(\mathrm{N}_{\mathrm{G}-1}, \mathrm{P}_{\mathrm{G}-1}\right),(1,1)\right]
$$


defines the upper (lower) portion of the factor use lens when industries have been sorted in terms of decreasing (increasing) skill intensity. Note that under the assumption of full employment, total factor endowments equal total factor use, or $\left(\mathrm{N}_{\mathrm{R}}, \mathrm{P}_{\mathrm{R}}\right)=\left(\mathrm{N}_{\mathrm{G}}, \mathrm{P}_{\mathrm{G}}\right)=(1,1)$.

In practice, we observe both aggregated regions and aggregated goods. Let the term "industry" refer to an aggregation of goods. The factor use of any particular observed industry is the sum of the usages of its less aggregated sub-industries or goods. Similarly, the factor endowment of any particular observed aggregate region is the sum of the endowments of its sub-regions. The skilled-worker use (endowment) of aggregate $a$ is the sum of the skilled worker use (endowment) of all the sub-aggregates, $b \in a$,

$$
\mathrm{n}_{\mathrm{a}}=\sum_{b \in a} \mathrm{n}_{\mathrm{b}} .
$$

Proposition 1: The area in an industry or region lens increases with disaggregation if its sub-aggregates are heterogeneous in factor intensity or factor abundance, respectively.

Proof: Our proof is for the factor use lens, but the same reasoning applies to the region lens. The number of industry aggregates is equal to $\mathrm{A}<\mathrm{G}$. Starting with $\mathrm{A}=1$, we have one aggregate, i.e. one industry encompassing all goods. The lens is a straight line along the diagonal of the unit factor space. Factor price equalization can occur only if region endowments are on this line.

If $\mathrm{A}=2$, then we have two aggregates. As long as the two aggregates differ in factor intensity, the industry lens has positive area. Thus, disaggregating from $A=1$ to $A=2$ increases the area of the lens from zero to some positive value. 
More generally, consider disaggregation from A aggregates to B disaggregates, where $G>B>A>1$. The industry lens is a series of line segments connecting $\left(\mathrm{N}_{\mathrm{b}-1}, \mathrm{P}_{\mathrm{b}-1}\right)$ and $\left(\mathrm{N}_{\mathrm{b}}, \mathrm{P}_{\mathrm{b}}\right)$. Because the point $\left(\mathrm{N}_{\mathrm{b}}, \mathrm{P}_{\mathrm{b}}\right)$ represents cumulative factor use of industry aggregate $b$, the factor use share of aggregate $b$ is $\left(\mathrm{n}_{\mathrm{b}}, \mathrm{p}_{\mathrm{b}}\right)=\left(\mathrm{N}_{\mathrm{b}}-\mathrm{N}_{\mathrm{b}-1}, \mathrm{P}_{\mathrm{b}}-\mathrm{P}_{\mathrm{b}-1}\right)$.

Pick any particular industry aggregate $a$ to disaggregate into $b \in a$. If $\left(\mathrm{n}_{\mathrm{a}}, \mathrm{p}_{\mathrm{a}}\right)$ represents the share of skilled and unskilled labor used in aggregate $a$, then the resulting distribution of skilled and unskilled workers into disaggregates can be represented with the set $\left\{\mathrm{n}_{\mathrm{ab}}, \mathrm{p}_{\mathrm{ab}}\right\}$, where

$$
\mathrm{n}_{\mathrm{a}}=\sum_{\mathrm{b} \in \mathrm{a}} \mathrm{n}_{\mathrm{ab}} \text { and } \mathrm{p}_{\mathrm{a}}=\sum_{\mathrm{b} \in \mathrm{a}} \mathrm{p}_{\mathrm{ab}} \text {. }
$$

Order $\left\{\mathrm{n}_{\mathrm{ab}}, \mathrm{p}_{\mathrm{ab}}\right\}$ according to increasing skill intensity. Any particular disaggregate industry $b$ will have a slope, $\mathrm{p}_{\mathrm{ba}} / \mathrm{n}_{\mathrm{ba}}$, that is either greater than, equal to, or less than the slope of the aggregate to which it belongs, $\mathrm{p}_{\mathrm{a}} / \mathrm{n}_{\mathrm{a}}$. If the slope of one of the disaggregate industries is less than that of the aggregate industry, then there must be at least one disaggregate industry with a slope that is greater than the aggregate industry.

Without loss of generality, if there are two disaggregates in $a, b$ and $b$, then disaggregation increases the area of the industry lens by the triangle

$$
\left\{\left(\mathrm{N}_{\mathrm{a}-1}, \mathrm{P}_{\mathrm{a}-1}\right),\left(\mathrm{N}_{\mathrm{ab}}, \mathrm{P}_{\mathrm{ab}}\right),\left(\mathrm{N}_{\mathrm{ab}}, \mathrm{P}_{\mathrm{ab}}\right)\right\} \text {. }
$$

Since this area is positive, lens size increases.

The top panel of Figure 2 illustrates the intuition behind Proposition 1. Assume we begin with three industry aggregates $(\mathrm{A}=3)$. Aggregate 1 is represented by the 
segment $\mathrm{OA}$, aggregate 2 by segment $\mathrm{AB}$, and aggregate 3 by $\mathrm{BC}$. The upper half of the lens is represented by the polygon $\mathrm{OABC}$. If we disaggregate the third aggregate into two sub-aggregates, the sum of the two resulting vectors must be equal to that of the original, third aggregate. As long as at least one sub-aggregate differs in skill intensity from its aggregate, the resulting triangle $\mathrm{BQC}$ has positive area, and the area of the lens increases with industry disaggregation. The bottom panel of Figure 2 illustrates how this increase in lens area is distributed across the lens by re-ordering the sub-aggregate industries according to their skill intensity.

Proposition 1 and Figure 2 indicate that finding a violation of the lens condition is sensitive to the relative aggregation of goods and regions. The likelihood of finding a violation of the lens condition increases with industry lens size (i.e., industry disaggregation) and decreases with region lens size (i.e., region aggregation). We now turn to an empirical demonstration of these implications.

\section{Mexico: An Empirical Example}

In this section, we show how varying the level of industry aggregation can induce both satisfaction and violation of the lens condition in Mexico.

\section{A. Data}

Mexico's industrial census is conducted by the Institutio Nactional de Estadística Geografia e Informatica (INEGI), Mexico's national statistical agency. We use manufacturing data from the 1986 and 1999 Industrial Censuses, which provide data for 
the year prior to the survey. ${ }^{5}$ The Census contains information on the employment of production (unskilled) workers (obreros) and non-production (skilled) workers (empleados), as well as aggregate payments to each type of worker (the wagebills). ${ }^{6}$ The most disaggregate level of industry categorization in the data is the six-digit Clasificación Mexicana de Actividades y Productos (CMAP). We construct lenses using six-, four-, three-, and two-digit CMAP industries, which break production into 314, 54, 29 and 9 aggregates, respectively. The data cover 32 Mexican regions (31 states and the Federal District, i.e., Mexico City).

B. Empirical Results

Figure 3 reports separate lenses for six-, four-, three- and two-digit CMAP industries and 32 Mexican regions for the most recent year of the sample, 1999. An alternate view of these lenses is provided in Figure 4, which graphs the vertical distance between region and industry lenses in the below-diagonal portion of the lenses against the cumulative share of unskilled labor. Figure 4 makes use of a convenient algorithm for automating the search for lens condition violations by checking numerically whether

$$
\min _{p}\left[N_{r}(P)-N_{i}(P)\right] \leq 0
$$

\footnotetext{
${ }^{5}$ More information about the Mexican Industrial Census can be found at http://www.inegi.gob.mx. ${ }^{6}$ Use non-production worker status as a proxy for skilled workers seems to capture much of the skill segregation between industries in Mexico. Robertson (2004) shows that Mexican production workers have less education in every industry than non-production workers, and that industries with a higher ratio of nonproduction workers also have higher average education levels.
} 
for $0<\mathrm{P}<1$. Non-positive differences in equation (6) indicate a violation of the lens condition because the cumulative endowment share of skilled workers is less than the cumulative industry use share of skilled workers.

Figures 3 and 4 summarize results for 1999. They demonstrate that the likelihood of finding a violation of the lens condition is sensitive to the relative disaggregation of industries and regions. The figures show that, holding the number of regions and therefore the region lens constant, industry disaggregation increases the relative distance between industry and region lenses. Thus, while the lens condition is violated for 2-digit industries, it is satisfied for 3-, 4- and 6-digit industries. The results in Figure 5 offer a similar conclusion for 1986.

Holding industry aggregation constant and increasing region aggregation renders satisfaction of the lens condition more likely in analogous fashion. We do not demonstrate this sensitivity here because there is no natural grouping of Mexican states into "super" states. Disaggregating Mexican states into smaller geographic areas which, as noted in the introduction, may more closely resemble the labor market areas implied by theory - on the other hand, increases region lens size and therefore increases the likelihood of finding a violation of the lens condition. We do not perform this exercise because confidentiality restrictions prohibit disclosure of results based on more disaggregate regional data (e.g. municipios or cities).

\section{Conclusions}

Deardorff's (1994) lens condition provides useful intuition about the theoretical conditions giving rise to factor price equality. Unfortunately, empirical implementation 


\section{Empirical Implementation of the Lens Condition}

of this condition is systematically biased by the level of aggregation of either regions or industries. This note demonstrates this point both theoretically and empirically. 


\section{References}

Davis, Donald R. and David E. Weinstein. "An Account of Global Factor Trade." American Economic Review, 91(5) December 2001, pp1423-54.

Deardorff, Alan V. "The Possibility of Factor Price Equalization, Revisited." Journal of International Economics, 36(2) February 1994, pp. 167-75.

Debaere, Peter. "Does Lumpiness Matter in an Open Economy? - Studying International Economics with Regional Data." Journal of International Economics, 64(2) December 2004, pp. 485-501.

Debaere, Peter and Ufuk Demiroglu. "On the Similarity of Country Endowments." Journal of International Economics, 59(1) January 2003, pp. 101-136.

Demiroglu, Ufuk and Kwan Koo Yun. "The Lens Condition for Factor Price Equalization.” Journal of International Economics 47(2) April 1999, pp. 449-456.

Dixit, Avinash and Victor Norman, Theory of International Trade, 1980, Cambridge University Press, Cambridge, UK.

Qi, Ling. "Conditions for Factor Price Equalization in the Integrated World Economy." Review of International Economics, 11(5), November 2003, pp. 899-908.

Robertson, Raymond "Relative Prices and Wage Inequality: Evidence from Mexico" Journal of International Economics 64(2), December 2004, pp. 387-409.

Schott, Peter K. "One Size Fits All? Heckscher-Ohlin Specialization in Global Production.” American Economic Reivew 93(2) June 2003, pp. 686-708.

Schott, Peter K. "Across-Product versus Within-Product Specialization in International Trade." Quarterly Journal of Economics 119(2), May 2004, pp. 647-678.

Wong, Siu-kee and Kwan Koo Yun. "The Lens Condition with Two Factors." Review of International Economics, 11(4), September 2003, pp 692-696.

Xiang, Chong. "The Sufficiency of the Lens Condition for Factor Price Equalization in the Case of Two Factors." Journal of International Economics, 53(2) April 2001, pp. 463-474.

Yun, Kwan Koo. "Similarity of Endowments and the Factor Price Equalization Condition." Economic Theory 21(2-3) March 2003, pp. 605-612. 
Figure 1: Deardorff's (1994) Lens Condition
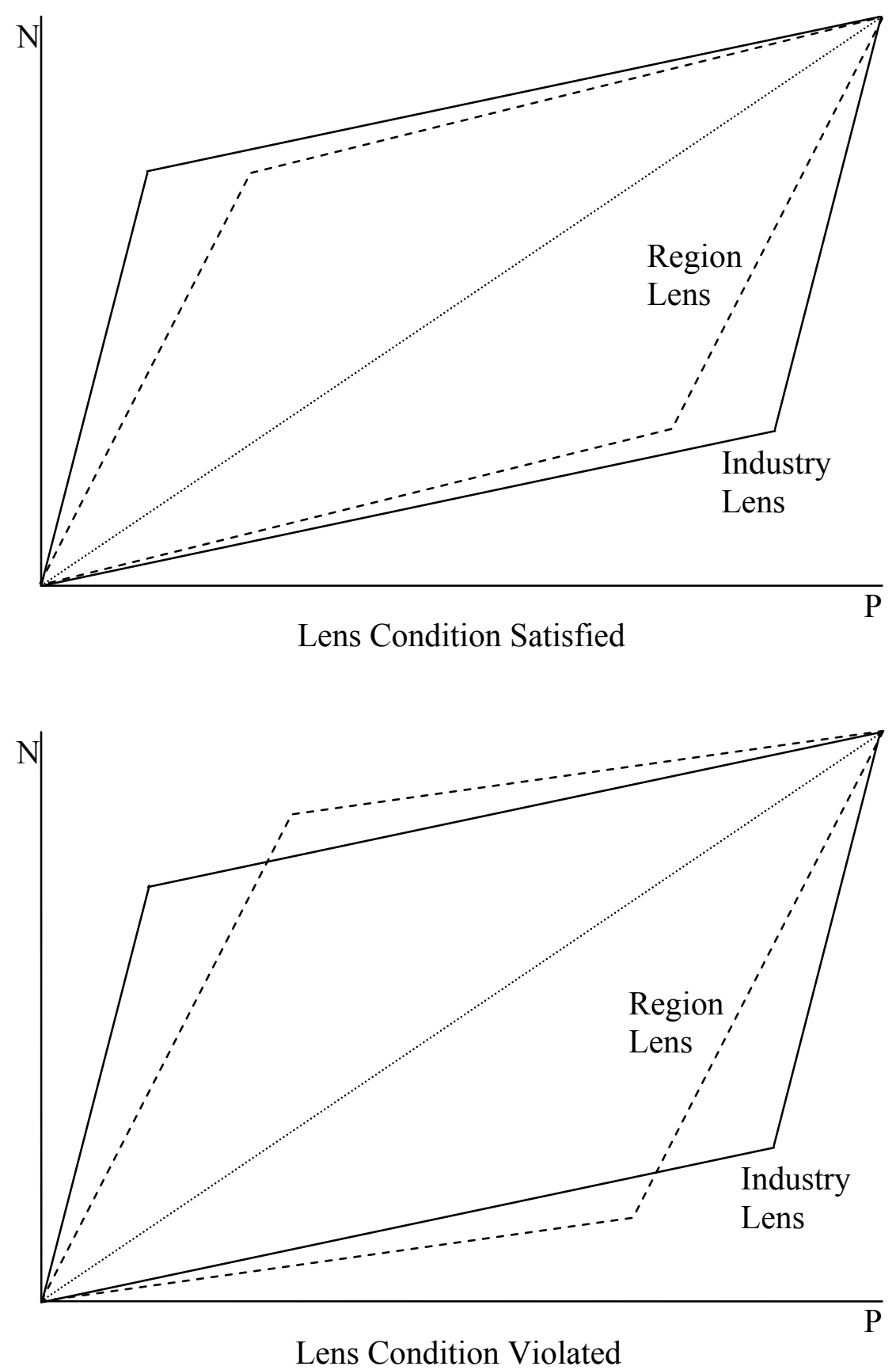
Figure 2: Data Disaggregation Increases Lens Area
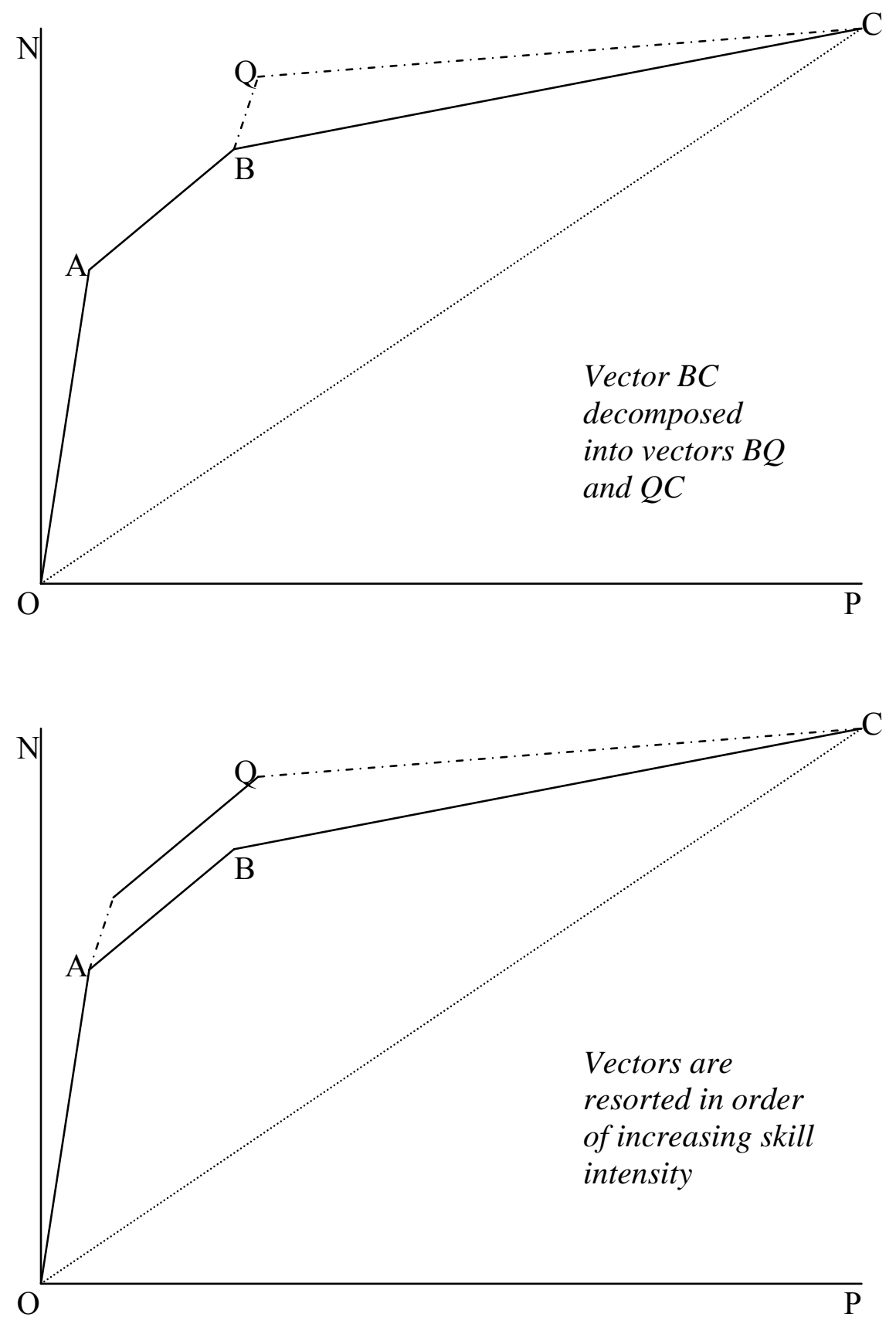


\section{Figure 3: Mexican Industry and Region Lenses, 1999}
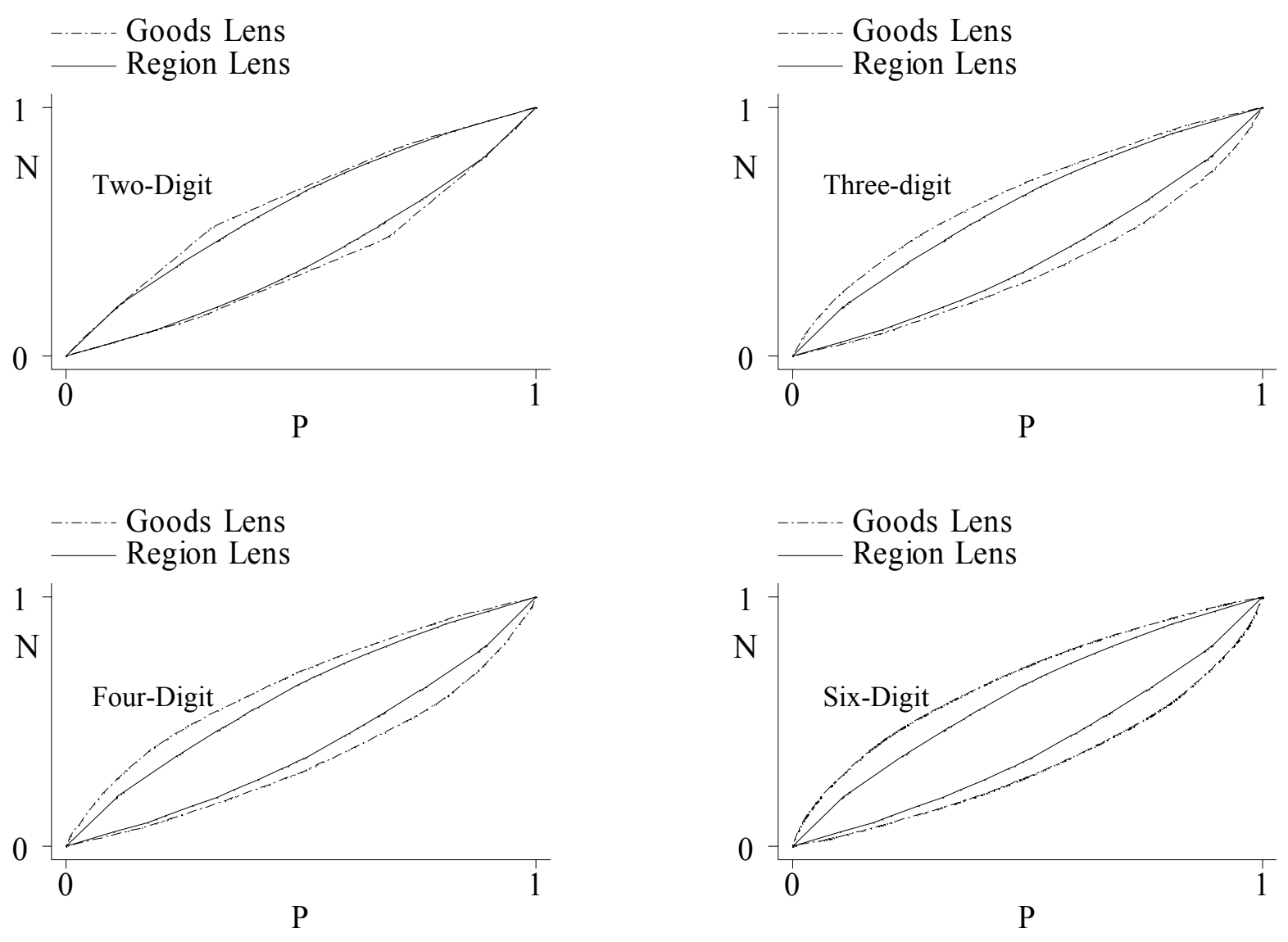

Notes: $\mathrm{N}$ and $\mathrm{P}$ represent cumulative endowments (region lens) and use (industry lens) of skilled and unskilled workers, respectively. The region lens is comprised of the 32 states in each panel. The industry lenses are constructed from 9 two-digit industries, 29 three-digit industries, 54 four-digit industries, or 314 six-digit industries, respectively. 


\section{Figure 4: Normalized Mexican Industry and Region Lenses, 1999}

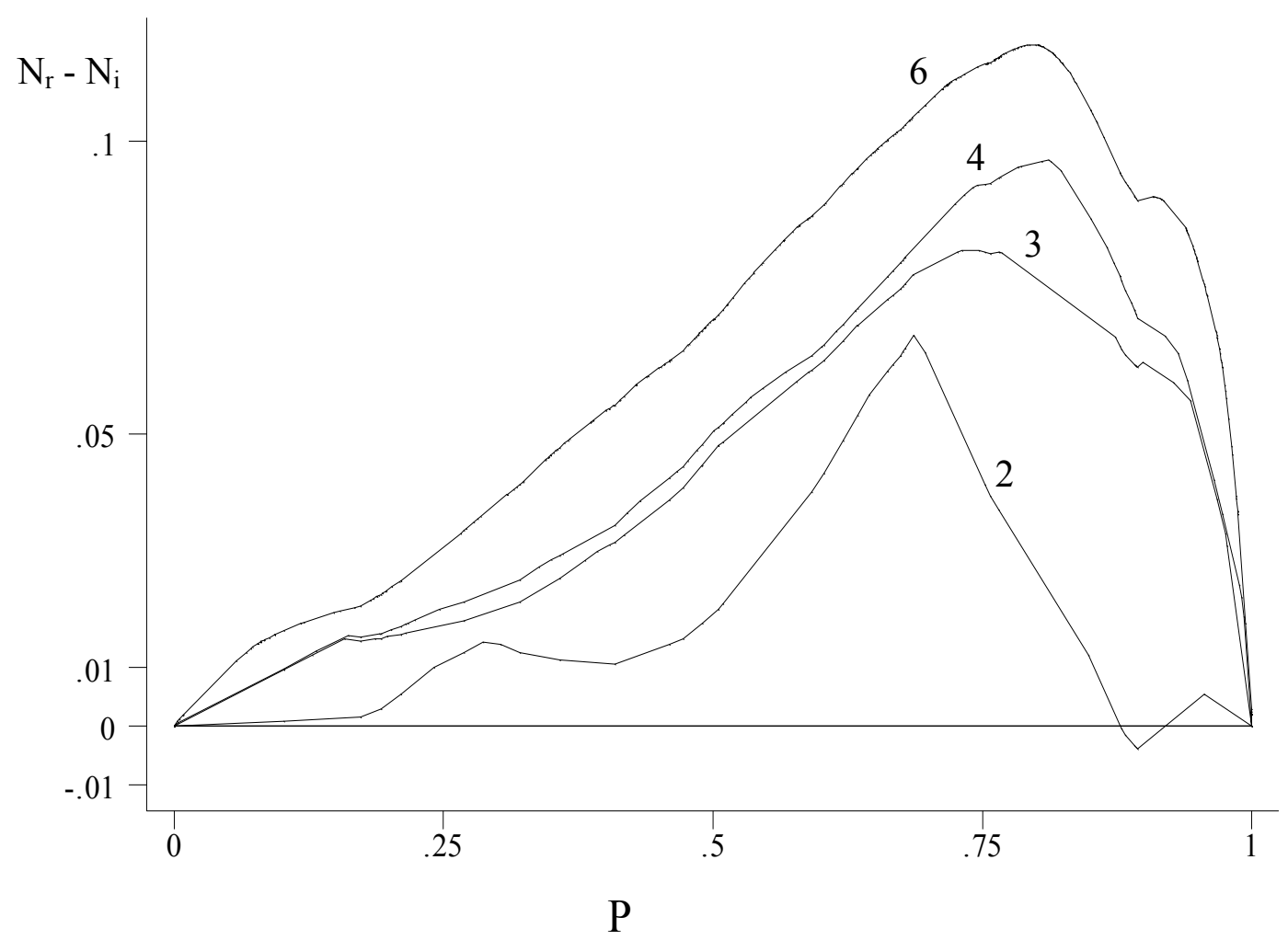

Notes: $\mathrm{N}$ and $\mathrm{P}$ represent cumulative endowments (region lens) and use (industry lens) of skilled and unskilled workers, respectively. The four lines in this graph represent four different levels of industry aggregation that correspond to Figure 3. The level of aggregation is denoted by the number closest to each curve. Each line represents the difference between the lower half of the (symmetric) regional lens and the lower half of the (symmetric) industry lens as a function of $\mathrm{P}$. The lens condition fails if the difference is zero or negative, which implies that the regional lens crosses (and therefore a part exists outside of) the industry lens. The regional lens is comprised of the 32 states. The industry lenses are constructed from, respectively, 9 two-digit industries, 29 threedigit industries, 54 four-digit industries, or 314 six-digit industries. 


\section{Figure 5: Normalized Mexican Industry and Region Lenses, 1986}

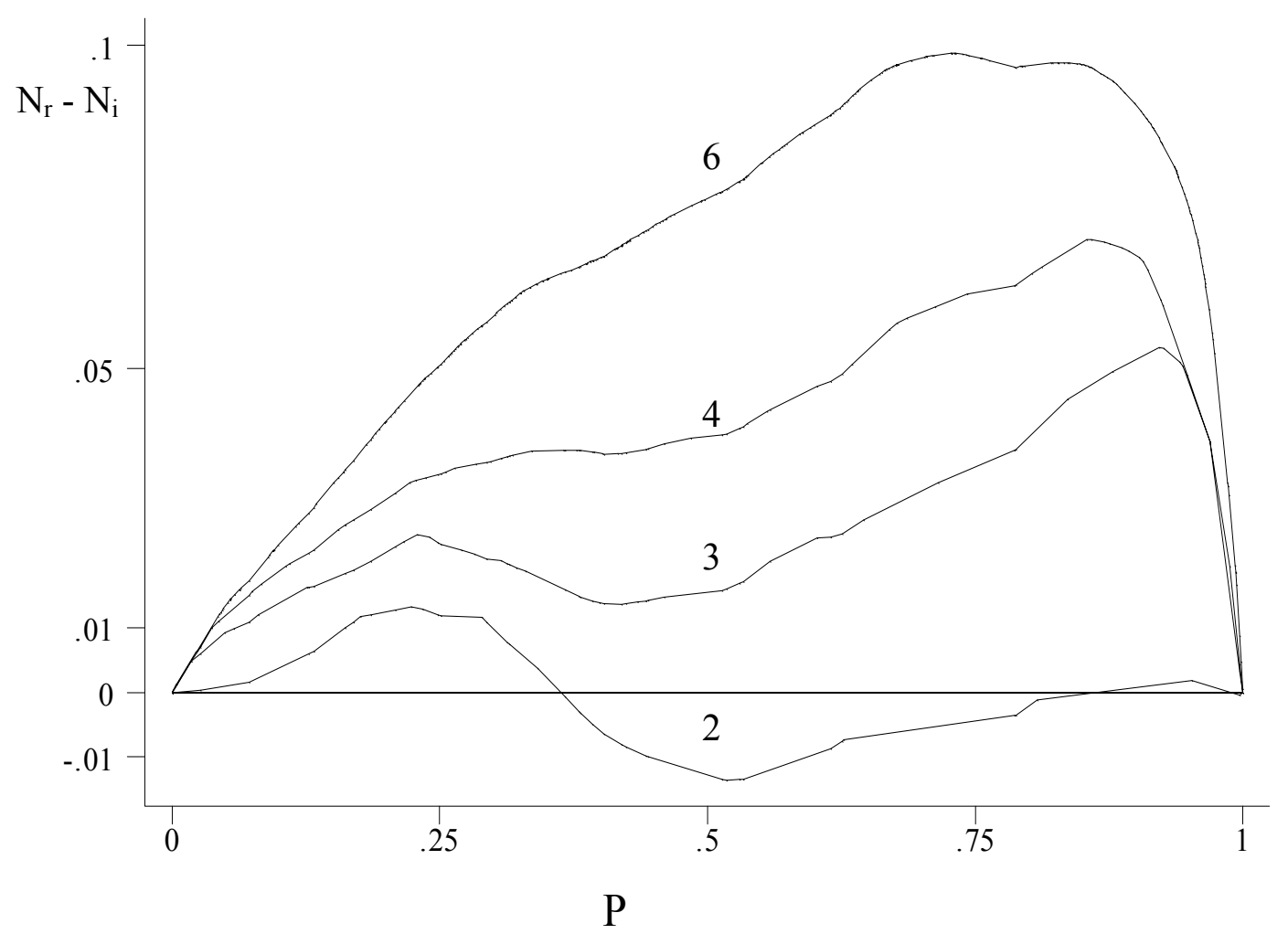

Notes: $\mathrm{N}$ and $\mathrm{P}$ represent cumulative endowments (region lens) and use (industry lens) of skilled and unskilled workers, respectively. The four lines in this graph represent four different levels of industry aggregation that correspond to Figure 3. The level of aggregation is denoted by the number closest to each curve. Each line represents the difference between the lower half of the (symmetric) regional lens and the lower half of the (symmetric) industry lens as a function of $\mathrm{P}$. The lens condition fails if the difference is zero or negative, which implies that the regional lens crosses (and therefore a part exists outside of) the industry lens. The regional lens is comprised of the 32 states. The four lines in this graph represent four different levels of industry aggregation, denoted by the number closest to each curve. The industry lenses are constructed from, respectively, 9 two-digit industries, 29 three-digit industries, 54 four-digit industries, or 314 six-digit industries. 